\title{
Aflibercept for choroidal neovascularizations secondary to pseudoxanthoma elasticum: a prospective study
}

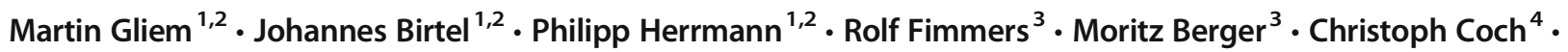 \\ Almut Wingen $^{4} \cdot$ Frank G. Holz ${ }^{1,2} \cdot$ Peter Charbel Issa ${ }^{5}$ (D)
}

Received: 8 August 2019 / Revised: 13 November 2019 / Accepted: 20 November 2019 / Published online: 20 December 2019

(C) The Author(s) 2019

\begin{abstract}
Purpose To evaluate the use of $2 \mathrm{mg}$ intravitreal aflibercept for treatment of choroidal neovascularization (CNV) secondary to angioid streaks in patients with pseudoxanthoma elasticum (PXE).

Methods In this 12-month prospective, open-label, uncontrolled, non-randomized interventional clinical trial, 15 PXE patients with CNV (mean age: 53 years, range 22-65) received one initial intravitreal injection of $2 \mathrm{mg}$ aflibercept. Further injections were based on CNV activity at monthly examinations. The primary endpoint was change of best corrected visual acuity (BCVA) after 12 months. Secondary outcomes were change of central retinal thickness (CRT), leakage from CNV, retinal sensitivity, and vision-related quality of life.

Results BCVA improved from $75.0 \pm 10.8( \pm$ SD, Snellen equivalent 20/32) to $79.3 \pm 7.3$ ETDRS letters (20/32) at final visit $(p=0.083)$. CRT decreased from $317 \pm 81$ to $279 \pm 51 \mu \mathrm{m}(p=0.004)$. Retinal sensitivity on microperimetry changed from 17.8 \pm 4.5 to $18.5 \pm 4.3 \mathrm{~dB}(p=0.103)$ and vision-related quality of life from a VQF-25 score of $80.7 \pm 10.4$ to $83.5 \pm 14.5(p=0.554)$. The mean number of injections was $6.7 \pm 2.6$, and 5 participants had persistent or reactivated CNV activity at final visit. The observed adverse events were comparable with studies on aflibercept for other indications.

Conclusion The results of this study indicate that intravitreal aflibercept is a treatment option for CNV secondary to PXE.
\end{abstract}

Keywords Pseudoxanthoma elasticum · ABCC6 · Angioid streaks $\cdot$ Choroidal neovascularization $\cdot$ Aflibercept $\cdot$ Anti-VEGF

Peter Charbel Issa was previously affiliated with the Department of Ophthalmology, University Hospital of Bonn.

Peter Charbel Issa

study-enquiry@outlook.com

1 Department of Ophthalmology, University Hospital of Bonn, Bonn, Germany

2 Centre for Rare Diseases Bonn (ZSEB), University of Bonn, Bonn, Germany

3 Institute of Medical Biometry, Informatics and Epidemiology, University of Bonn, Bonn, Germany

4 Study Center Bonn, Institute of Clinical Chemistry and Clinical Pharmacology, University Hospital Bonn, Bonn, Germany

5 Oxford Eye Hospital, Oxford University Hospitals NHS Foundation Trust, and Nuffield Laboratory of Ophthalmology, Department of Clinical Neurosciences, University of Oxford, Oxford, UK

\section{Introduction}

Pseudoxanthoma elasticum (PXE, OMIM \#264800) is a rare multi-system disease with autosomal recessive inheritance. PXE is caused by biallelic mutations in the $A B C C 6$ gene which codes for a transmembrane protein that is mainly expressed in the liver [1]. Lack or reduced function of ABCC6 leads to increased calcification of tissue rich in elastic fibers, hence explaining the major manifestations of the disease, i.e., whitish-yellowish skin changes, early-onset arteriosclerosis, and characteristic ocular changes driven by calcification of Bruch's membrane [2]. Decreased pyrophosphate levels are thought to play an important role in the disease process, but the exact pathogenic pathways are still unknown $[3,4]$.

The ocular phenotype is characterized by so-called peau d'orange which marks the transition zone between the centrally calcified and peripheral uncalcified Bruch's membrane, peripheral chorioretinal atrophic spots (comet lesions), and angioid streaks which represent breaks 
within the thickened and brittle Bruch's membrane [5-7]. At later stages, macular atrophy may develop, or the disease course may be complicated by choroidal neovascularizations $(\mathrm{CNV})$ that typically originate from angioid streaks [7-9].

The risk for developing CNV is already significant in the 5th decade and increases further with age [8]. If left untreated, PXE patients with CNV may develop rapid and irreversible loss of central vision [10]. Among PXE-related morbidities, visual impairment most severely affects the patients' quality of life [11, 12].

The development of intravitreal anti-vascular endothelial growth factor (VEGF) agents has significantly improved the visual prognosis of patients with PXE-related CNV. Good evidence exists for the efficacy of intravitreal bevacizumab and ranibizumab [10]. Another intravitreal VEGF inhibitor is aflibercept, which is a fusion protein of the extracellular domains of the VEGF receptor 1 and 2 and the Fc fragment of human IgG potentially blocking all isoforms of VEGF A and placental growth factor $[13,14]$. The efficacy of intravitreal aflibercept is proven for $\mathrm{CNV}$ secondary to AMD [15] and myopia [16]. Evidence for efficacy for the treatment of CNV secondary to angioid streaks in PXE patients is limited to few case reports [17-20]. In addition, there is one small prospective study on ranibizumab-pretreated patients with a CNV secondary to angioid streaks reporting favorable outcomes, which, however, was not specific for PXE patients [21]. Therefore, it was the aim of this study to prospectively investigate the use of intravitreal aflibercept for treatment-naïve and pretreated CNV in patients with PXE.

\section{Methods}

\section{Study design and population}

This prospective, open-label, uncontrolled, nonrandomized interventional clinical trial included 15 patients with CNV secondary to PXE. Patients were recruited between September 2015 and July 2017 at the Department of Ophthalmology, University of Bonn, which is a tertiary referral center for patients with PXE in Germany. The study was in adherence with the Declaration of Helsinki. IRB approval was obtained from Ethikkommission der Medizinischen Fakultät, Rheinische Friedrich-Wilhelms-Universität Bonn; clinicaltrials.gov identifier: NCT02537054, and written consent was obtained from each participant. The initially intended recruitment of 20 patients was reduced to 15 patients during the study due to a prolonged recruitment phase. The primary endpoint was change of BCVA after 12 months compared to baseline. Secondary outcomes were change compared to baseline of central retinal thickness (CRT), leakage from CNV, retinal sensitivity, and vision-related quality of life.

The inclusion criteria were the diagnosis of an active CNV secondary to PXE and age between 18 and 65 years. The diagnosis of PXE was based on typical ophthalmologic findings and confirmed by genetic testing. Exclusion criteria were any pretreatment for $\mathrm{CNV}$ other than intravitreal bevacizumab or ranibizumab, treatment with intravitreal bevacizumab or ranibizumab within 30 days prior to study inclusion (irrespective from the treatment response), and any other ocular pathology known to potentially interfere with the outcome measures, e.g., uncontrolled glaucoma, uncontrolled ocular inflammation, retinal vascular disease, or subfoveal fibrosis.

\section{Study treatment}

All 15 patients received one initial intravitreal injection of $2 \mathrm{mg}$ aflibercept into the study eye. Further injections were based on monthly assessment of persistent or recurrent $\mathrm{CNV}$ activity. Criteria for repeat injections were new or persistent sub- or intraretinal fluid, increased detachment of the retinal pigment epithelium, retinal thickening, new intra- or subretinal hemorrhages, and/or loss of visual acuity caused by the CNV. Intravitreal aflibercept is not labeled for the treatment of CNV secondary to angioid streaks, and hence its use for this indication is still investigational.

\section{Assessments}

A complete ophthalmologic examination was performed at each visit including assessment of BCVA, indirect ophthalmoscopy, assessment of intraocular pressure, fundus photography, and spectral-domain optical coherence tomography (SD-OCT). Fluorescein angiography and microperimetry were performed at baseline, after 6 months and at final visit.

A standard ETDRS chart and protocol were used for measuring BCVA, which was scored based on the total number of letters read correctly.

SD-OCT images (HRA-OCT, Heidelberg Engineering, Heidelberg, Germany) were acquired using a standardized protocol consisting of horizontal and vertical line scans centered to the fovea, a volume scan recorded in the high speed mode covering 30 degrees (horizontal) $\times 25$ degrees (vertical) centered on the fovea, with a distance of approximately $120 \mu \mathrm{m}$ between individual scans. Assessment of CRT was based on the mean thickness within the central subfield of an overlaid ETDRS grid centered to the fovea as provided by the Heidelberg Eye Explorer. The automated segmentation was checked by the investigator and manually corrected if needed.

Fluorescein angiography (FA) was performed using a scanning laser ophthalmoscope (HRA-OCT and HRA2 
Heidelberg Engineering, Heidelberg, Germany) and a standardized protocol with $30^{\circ}$ field of view centered to the fovea and frames at $0.5,1,5$, and $10 \mathrm{~min}$.

For microperimetry testing, patients were dark adapted for $10 \mathrm{~min}$ in dim light and subsequently examined using the MAIA microperimeter (CenterVue, Padua, Italy) using a dedicated grid consisting of 68 test points. Retinal sensitivity was measured as mean sensitivity of all measured points. The baseline examination was incorrect for one patient resulting in an exclusion from the microperimetry analysis.

Vision-related quality of life was assessed using the National Eye Institute 25-Item Visual Function Questionnaire (NEI VFQ-25) at baseline and final visit [22].

\section{Statistical analysis}

Statistical analyses were performed using R (R System for Statistical Computing, version 3.4.3). Continuous outcome measures (BCVA, central retinal thickness, retinal sensitivity, and quality of life) at baseline and month 12 are described using means and standard deviations (SD). Mean differences between baseline and month 12 were calculated along with $95 \%$ confidence intervals. Additionally, the measures at the two points in time were compared using Wilcoxon rank-sum tests. Differences regarding leakage from a $\mathrm{CNV}$ on FA were compared using a McNemar test. A two-sided $p<0.05$ was considered significant.

\section{Results}

\section{Baseline demographic and ocular characteristics}

Detailed baseline characteristics of the 15 enrolled patients are shown in Table 1. Mean age was 53 years (range 22-64), 10 patients were female. In the study eye, mean BCVA was 75.0 $\pm 10.8( \pm$ SD) ETDRS letters (Snellen equivalent 20/32, Table 2). Six of the study eyes were treatment-naïve while the remaining 9 eyes had received a mean of 11.8 injections with ranibizumab and/or bevacizumab prior to study inclusion. Baseline BCVA of the treatment-naïve and pretreated eyes was $80.5 \pm 4.8$ and $71.3 \pm 12.3$ ETDRS letters, respectively (Table 2). Fellow eyes are not reported because disease presentation was highly variable and routine treatment in case of $\mathrm{CNV}$ activity was independent from the study eye.

\section{Best corrected visual acuity}

At final visit, mean BCVA had improved to $79.3 \pm 7.3$ ETDRS letters (Snellen equivalent 20/32; change: $+4.3 \pm$ $8.2,95 \%$ confidence interval -0.3 to +8.8 , Fig. 1a). Ten eyes had a stable BCVA with $<5$ letters gained or lost. Improvement of $\geq 5$ and $<10$ letters was observed in 1 eye and $\geq 10$ letters in 3 eyes. There was a tendency to higher BCVA gains in patients with a lower baseline BCVA (Fig. 1b), and accordingly, only the subgroup of eyes with a baseline BCVA $\leq 20 / 40$ showed a significant

Table 1 Baseline characteristics of patients

\begin{tabular}{lllllll}
\hline Patient No. & Sex & Age & Study Eye & Visual acuity & Prior intravitreal injections of VEGF inhibitors * \\
\cline { 5 - 7 } & & & & Study eye & Number & $\begin{array}{c}\text { Interval before study } \\
\text { inclusion (month(s)) }\end{array}$ \\
\hline 1 & & & & & - \\
2 & F & 53 & OD & $20 / 20$ & 0 & 2 \\
3 & M & 53 & OD & $20 / 63$ & 11 & 1 \\
4 & M & 43 & OS & $20 / 50$ & 27 & - \\
5 & F & 22 & OD & $20 / 100$ & 1 & - \\
6 & F & 55 & OS & $20 / 32$ & 0 & 3 \\
7 & F & 57 & OS & $20 / 20$ & 0 & - \\
8 & M & 45 & OD & $20 / 25$ & 34 & - \\
9 & M & 60 & OS & $20 / 20$ & 14 & - \\
10 & M & 64 & OS & $20 / 40$ & 0 & 2 \\
11 & F & 65 & OD & $20 / 20$ & 0 & 5 \\
12 & F & 64 & OD & $20 / 25$ & 1 & 1 \\
13 & F & 57 & OD & $20 / 40$ & 14 & 1 \\
14 & F & 51 & OS & $20 / 25$ & 3 & 1 \\
15 & F & 55 & OD & $20 / 63$ & $20 / 20$ & 0 \\
\hline
\end{tabular}

*Ranibizumab or bevacizumab in the study eye 
Table 2 Outcome after 12 months

\begin{tabular}{llll}
\hline & $\begin{array}{l}\text { Baseline } \\
( \pm \mathrm{SD})\end{array}$ & $\begin{array}{l}\text { Month } 12 \\
( \pm \mathrm{SD})\end{array}$ & $\begin{array}{l}\text { Change } \\
( \pm \mathrm{SD} ; 95 \% \mathrm{CI})\end{array}$ \\
\hline Visual acuity (ETDRS letters) $(n=15)$ & $75.0 \pm 10.8$ & $79.3 \pm 7.3$ & $+4.3 \pm 8.2 ;-0.3$ to 8.8 \\
$\quad$ Treatment-naïve $(n=6)$ & $80.5 \pm 4.8$ & $84.0 \pm 3.5$ & $+3.5 \pm 5.8 ;-2.6$ to 9.6 \\
Pretreated $(n=9)$ & $71.3 \pm 12.3$ & $76.1 \pm 7.6$ & $+4.8 \pm 9.9 ;-2.8$ to 12.4 \\
Baseline BCVA $\leq 20 / 40(n=6)$ & $64.0 \pm 8.4$ & $74.2 \pm 7.4$ & $+10.2 \pm 8.3 ; 1.4$ to 18.9 \\
Baseline BCVA $>20 / 40(n=9)$ & $82.3 \pm 2.9$ & $82.7 \pm 5.2$ & $+0.3 \pm 5.7 ;-4.0$ to 4.7 \\
Central retinal thickness $(\mu \mathrm{m})(n=15)$ & $317 \pm 81$ & $279 \pm 51$ & $-38 \pm 42 ;-62$ to -15 \\
Treatment-naïve $(n=6)$ & $305 \pm 49$ & $271 \pm 41$ & $-34 \pm 27 ;-62$ to -6 \\
Pretreated $(n=9)$ & $325 \pm 100$ & $284 \pm 58$ & $-40 \pm 52 ;-80$ to -1 \\
Baseline BCVA $\leq 20 / 40(n=6)$ & $338 \pm 121$ & $282 \pm 78$ & $-56 \pm 49 ;-108$ to -5 \\
Baseline BCVA $>20 / 40(n=9)$ & $303 \pm 44$ & $277 \pm 27$ & $-26 \pm 35 ;-53$ to 1 \\
Retinal sensitivity $(\mathrm{dB})(n=14)$ & $17.8 \pm 4.5$ & $18.5 \pm 4.4$ & $+0.7 \pm 1.4 ;-0.1$ to 1.5 \\
Treatment-naïve $(n=6)$ & $19.0 \pm 3.0$ & $19.5 \pm 3.6$ & $+0.6 \pm 1.8 ;-1.3$ to 2.4 \\
Pretreated $(n=8)$ & $16.9 \pm 5.4$ & $17.7 \pm 5.0$ & $+0.8 \pm 1.1 ;-0.2$ to 1.7 \\
Baseline BCVA $\leq 20 / 40(n=6)$ & $16.9 \pm 5.1$ & $17.9 \pm 5.1$ & $+0.9 \pm 1.2 ;-0.3$ to 2.2 \\
Baseline BCVA $>20 / 40(n=8)$ & $18.5 \pm 4.3$ & $19.0 \pm 4.2$ & +0.03 \\
\hline
\end{tabular}

improvement in BCVA (Table 2). Only one participant lost $\geq 5$ letters.

\section{Structural outcomes}

Mean central retinal thickness (CRT) decreased from $317 \pm$ $81 \mu \mathrm{m}$ at baseline to $279 \pm 51 \mu \mathrm{m}$ at final visit (change: -38 $\pm 42 \mu \mathrm{m} ; 95 \% \mathrm{CI}-62$ to $-15 \mu \mathrm{m}$, Fig. 1c). In 4 patients, reduction was $>50 \mu \mathrm{m}$ and in one patient $>100 \mu \mathrm{m}$. Generally, the reduction of CRT was more pronounced in eyes with higher baseline CRT (Fig. 1d). The mean reduction of CRT was $34 \mu \mathrm{m}$ in the treatment-naïve and $40 \mu \mathrm{m}$ in pretreated subgroups, respectively. Eyes with BCVA $\leq 20 / 40$ showed a reduction of CRT of $-56 \mu \mathrm{m}$ compared with $26 \mu \mathrm{m}$ in eyes with baseline BCVA > 20/40 (Table 2). The largest effect on CRT was observed after the first aflibercept injection (Fig. 1c).

At baseline, 13 of the 15 study eyes showed clear leakage from a CNV on FA. Notably, the two remaining eyes were pretreated (interval since last treatment 4 and 5 months,
Fig. 1 Graphs illustrating change of mean best corrected visual acuity (BCVA) and central retinal thickness (CRT, C) at baseline and during study ( \pm standard error of the mean). The right graphs show the change of BCVA (B) and CRT (D) of all individual participants at final visit compared with baseline a
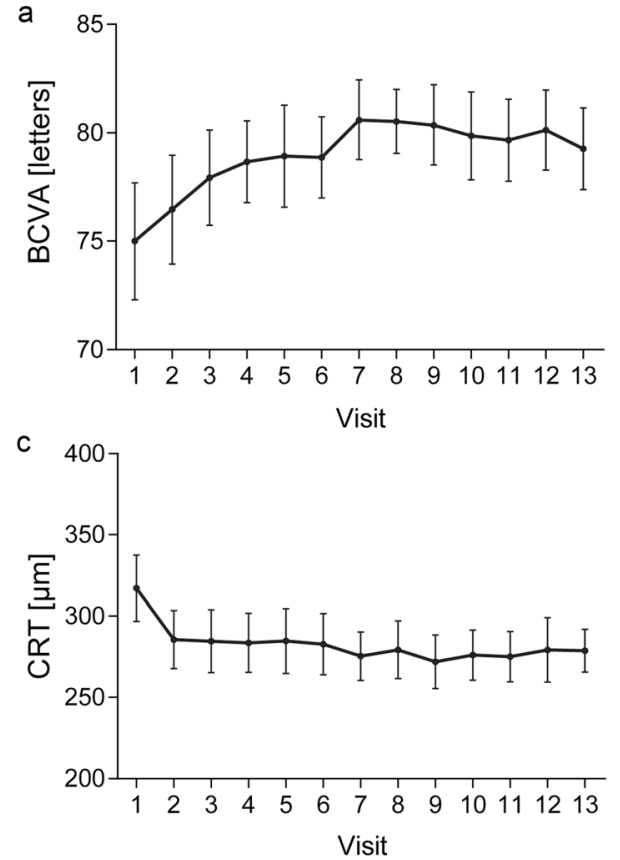
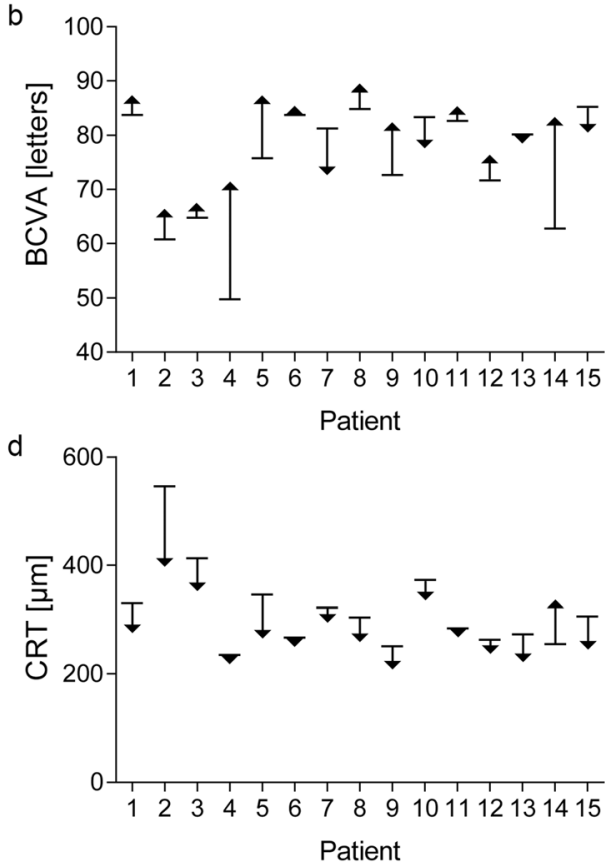
respectively) and showed extrafoveal fibrotic changes which may have affected the grading; however, clear evidence of $\mathrm{CNV}$ activity was present on OCT imaging. At final visit, leakage was absent in 8 of the initial 13 eyes with leakage. The remaining 5 eyes showed angiographic leakage and retinal thickening on OCT imaging indicating persistent or recurrent $\mathrm{CNV}$ activity. These eyes received continued anti-VEGF treatment around the time of the final study visit.

Representative examples of eyes at baseline and at last study visit are shown in Fig. 2.

\section{Retinal sensitivity and quality of life}

Mean retinal sensitivity on microperimetry improved from $17.8 \pm 4.5 \mathrm{~dB}$ at baseline to $18.5 \pm 4.4 \mathrm{~dB}$ at last visit (change: $+0.7 \pm 1.4 ; 95 \% \mathrm{CI}-0.1$ to 1.5 , Table 2 ). Four eyes lost $>$ $0.5 \mathrm{~dB}$ and 8 eyes gained $>0.5 \mathrm{~dB}$ during the study. Overall, 87 test points improved $\geq 5 \mathrm{~dB}$ and $45 \geq 10 \mathrm{~dB}$ whereas 35 test points decreased $\geq 5 \mathrm{~dB}$ and $21 \geq 10 \mathrm{~dB}$. Change of retinal sensitivity on microperimetry testing was similar in subgroups with different BCVA level $(\leq 20 / 40$ versus $>20 / 40)$ or differ- ent treatment history (naïve versus pretreated) (Table 2).

The mild improvement of the vision-related quality of life score from $80.7 \pm 10.4$ points at baseline to $83.5 \pm 14.5$ points at last visit (change: $+2.9 ; 95 \%$ CI -5.0 to +10.8 ) was not statistically significant $(p=0.55)$.

\section{Treatment exposure}

The mean number of injections over a period of 12 month was $6.7 \pm 2.6$ injections. Treatment-naïve eyes received $4.6 \pm 1.5$ and pretreated eyes $8.3 \pm 2.1$ injections. The number of injections was higher in the group with baseline BCVA $\leq 20 / 40$ $(8.2 \pm 2.0)$ then in those with BCVA $>20 / 40(6.0 \pm 2.5)$.

\section{Safety}

During the study, 5 ocular adverse events were documented that were likely associated with the study medication/ procedure (increased intraocular pressure in 2 participants, mild conjunctival hemorrhage in 2 participants and foreign body sensation after the injection in 1 participant). These

\section{Baseline}
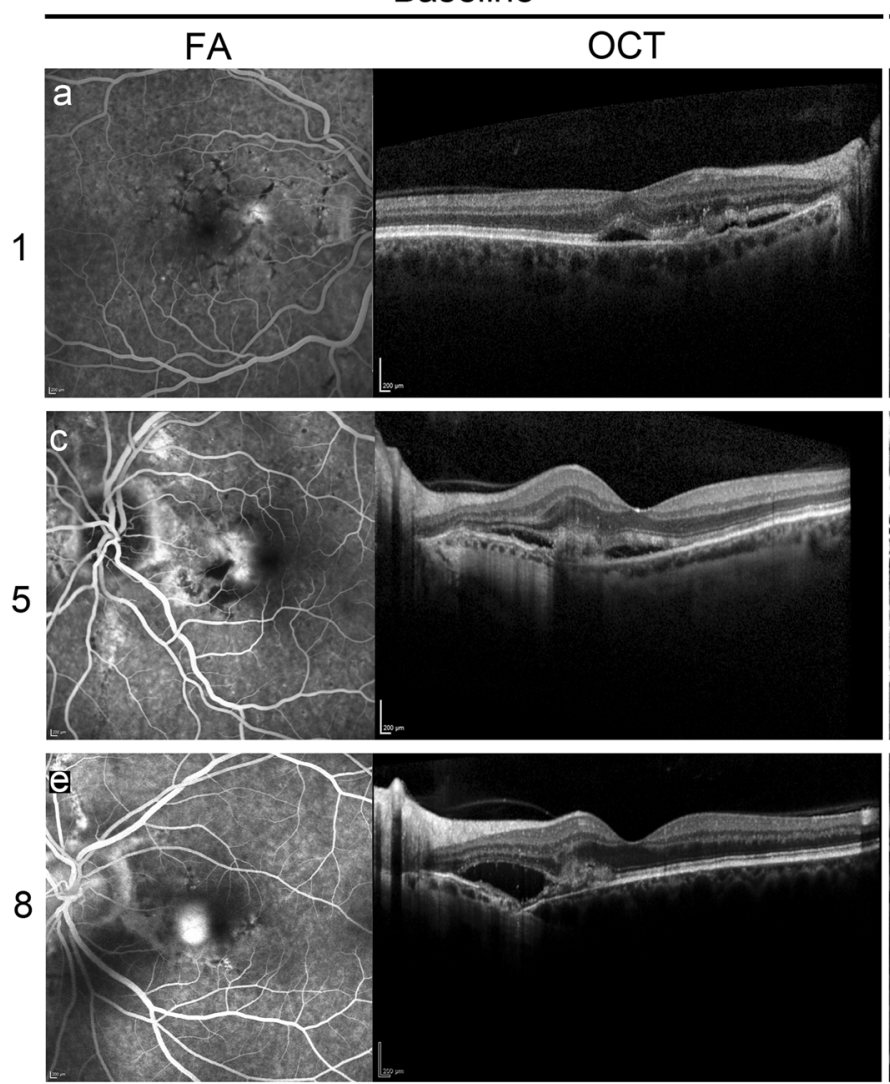

Fig. 2 Representative fluorescein angiography (FA) and optical coherence tomography (OCT) images of included patients with a CNV secondary to pseudoxanthoma elasticum with angioid streaks either treatment-naïve (a-d) or pretreated with anti-VEGF drugs (e and $\mathbf{f})$ at baseline

\section{Last Follow-up}
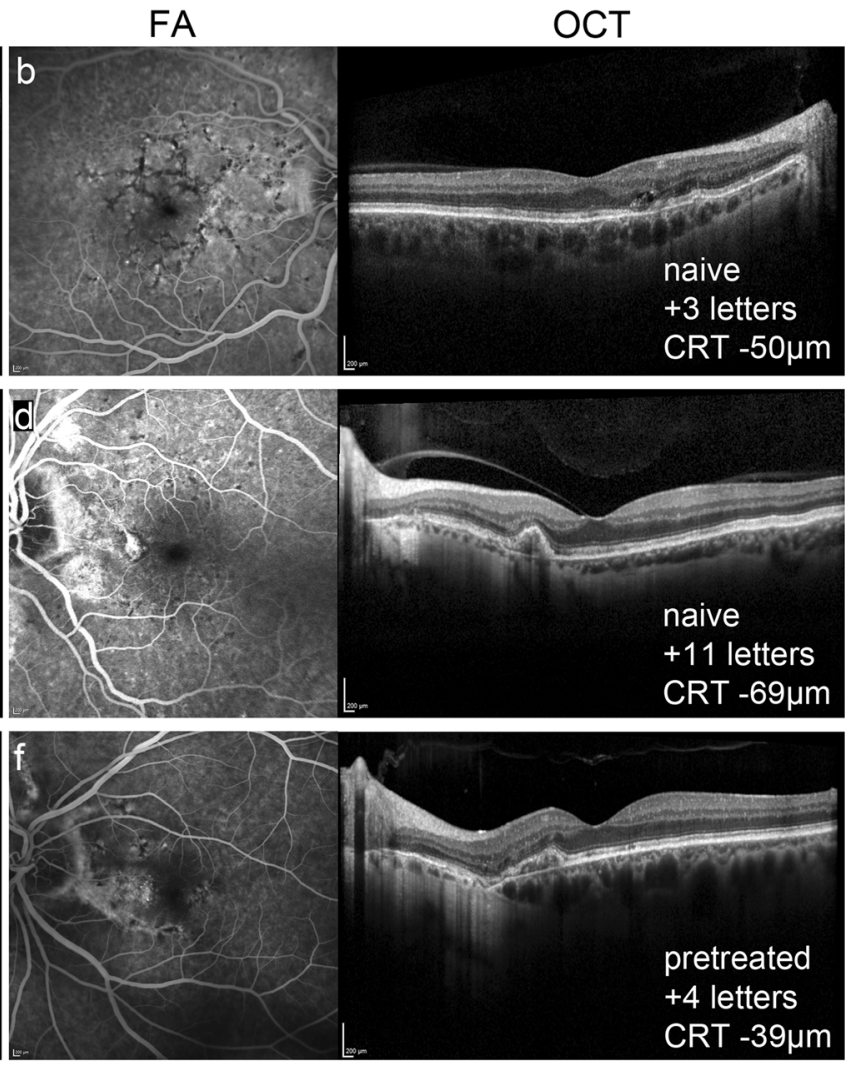

(left column) and last follow-up (right column) after 12 months. The numbers on the left represent the patient number. CRT: central retinal thickness 
events were all graded as mild to moderate and resolved without treatment. There was no case of endophthalmitis. In addition, 22 systemic adverse events were noted, which were generally graded as mild to moderate. Two were graded as serious adverse events (one was an intracardiac catheter after an STelevation on ERG examination, and the other surgery for an umbilical hernia). In all systemic adverse events, including the 2 serious adverse events, the causality with the study medication/procedure was graded as unlikely.

\section{Discussion}

In this prospective study, treatment with $2 \mathrm{mg}$ intravitreal aflibercept improved or stabilized BCVA in the majority of patients with PXE-associated CNV during a review period of 12 months. Concurrently, central retinal thickness decreased, leakage from active CNV was reduced, and retinal sensitivity on microperimetry improved. No uncommon or unexpected adverse event was observed. Accordingly, these results indicate that intravitreal aflibercept may be a treatment option for $\mathrm{CNV}$ associated with angioid streaks in PXE patients.

To our knowledge, this represents the first prospective study using aflibercept for CNV exclusively in patients with PXE. The results are in accordance with few previous case reports [17-20] as well as with one small prospective study on CNV secondary to angioid streaks [21] and indicate comparable efficacy and safety as intravitreal bevacizumab and ranibizumab, which are widely used for the treatment of PXE related CNV [10].

At first glance, the results of this study with a mean gain of 4.3 ETDRS letters might seem less favorable compared with previous studies using other anti-VEGF agents. One comparable prospective study using monthly intravitreal ranibizumab injections for PXE-associated CNV reported an improvement of 12 ETDRS letters over a period of 12 month [23]. In addition, the randomized, placebo-controlled MINERVA study, which investigated the efficacy of intravitreal ranibizumab for the treatment of $\mathrm{CNV}$ due to other causes than AMD or myopia, included a subgroup of 27 eyes with angioid streak-related CNV that gained 11 EDTRS letters after 2 intravitreal injections [24]. However, baseline BCVA in these studies was worse (61 and 62 ETDRS letters) compared with the study reported herein (75 ETDRS letters). Patients with good BCVA were not excluded from participating in the current study in order to match the real-world situation, hence explaining differences of baseline BCVA compared with other studies. Of note, patients enrolled herein with lower baseline BCVA also had the largest improvement. Inclusion of eyes with BCVA of up to 20/20 results in less potential improvement (ceiling effect). Moreover, regression to the mean may additionally favor larger vision gains when preselecting eyes with worse vision. Both effects may also need to be considered when interpreting the higher effect sizes of eyes with lower baseline BCVA in this study.

Another confounder in this study was that both, treatment-naïve and pretreated eyes were included. Although visual acuity gain was comparable, treatment-naïve eyes had the overall better baseline and final BCVA. Treatment-naïve eyes with their favorable baseline characteristics received fewer injections indicating overall less diseases activity in this subgroup.

Cardiovascular complications such as stroke or cardiac infarction are a well-known complication of PXE [25]. Therefore, particular attention needs to be paid to cardiovascular adverse events when using anti-VEGF drugs in patients with PXE. One patient in this study experienced an asymptomatic ST-elevation on ERG examination followed by an uneventful intracardiac catheter examination, which was, however, graded as not likely associated with the study medication/procedure. Hence, although no definitive conclusions can be drawn due to small sample size and limited review period, the safety profile of intravitreal aflibercept in PXE patients seems comparable with other intavireal anti-VEGF drugs and in favor of treatment.

There are some limitations of this study. The relatively small sample size due to the rareness of the disease, and the heterogeneous cohort due to high phenotypic variability of PXErelated retinopathy may limit general conclusions [26]. Various parameters including the severity of disease manifestation in the fellow eye, dark adaptation, or contrast vision were not considered in this study, but may have influenced the outcome of the vision-related quality of life assessment [27]. Furthermore, although prospective, the study had no control group, e.g., with placebo treatment. This was based on the following considerations: First, withholding treatment in a control group can be associated with irreversible loss of vision, and some treatment options (e.g., photodynamic therapy) may result in significantly worse outcomes, which would both not be acceptable for a control group from an ethical point of view [10]. Second, the current gold standard for treatment are intravitreal anti-VEGF agents, but the only randomized, placebo-controlled study using ranibizumab had not been published at the time our study was conducted [24]. However, we speculate that any potential difference in a head-to-head trial with another anti-VEGF agent would have been unlikely to be detected due to the low number of patients included in this study. Third, the study included patients with BCVA of 20/20 minimizing treatment effects detectable using BCVA as primary outcome measure.

Overall, the results of this study indicate that intravitreal aflibercept is a treatment option for $\mathrm{CNV}$ associated with PXE. This expands the spectrum of available treatment options in patients with PXE which may be of particular value in cases with poor response to other treatment options. 
Funding information This work was supported by Bayer Vital GmbH, Leverkusen, Germany. Dr. Charbel Issa received support from the National Institute for Health Research (NIHR) and Oxford Biomedical Research Centre (BRC), UK. The sponsor or funding organization had no role in the design or conduct of this research; collection, management, analysis, and interpretation of the data. The authors alone were responsible for the content and writing of the paper. The views expressed are those of the authors and not necessarily those of the NHS, the NIHR, or the Department of Health

\section{Compliance with ethical standards}

Conflict of interest Dr. Gliem is now employee and equity owner of F. Hoffmann-La Roche Ltd., Basel, Switzerland (since July 2019); he received financial support from Bayer AG and Heidelberg Engineering. Dr. Birtel received financial support from Heidelberg Engineering. Dr. Holz is consultant of Bayer AG, Heidelberg Engineering, and CenterVue. The Department of Ophthalmology, University Hospital of Bonn, Bonn, Germany, receives imaging devices from Heidelberg Engineering and CenterVue. Dr. Charbel Issa is consultant of Inozyme and received research support from Heidelberg Engineering. None of the authors has a proprietary interest in this study.

Ethical approval All procedures performed in studies involving human participants were in accordance with the ethical standards of the institutional and/or national research committee and with the1964 Helsinki Declaration and its later amendments or comparable ethical standards. The study protocol and study documents were approved by the local ethics committee (Ethikkommission der Medizinischen Fakultät, Rheinische Friedrich-Wilhelms-Universität Bonn; Lfd. Nr. 056/15AMG-ff). This article does not contain any studies with animals performed by any of the authors.

Informed consent Informed consent was obtained from all individual participants included in the study.

Open Access This article is licensed under a Creative Commons Attribution 4.0 International License, which permits use, sharing, adaptation, distribution and reproduction in any medium or format, as long as you give appropriate credit to the original author(s) and the source, provide a link to the Creative Commons licence, and indicate if changes were made. The images or other third party material in this article are included in the article's Creative Commons licence, unless indicated otherwise in a credit line to the material. If material is not included in the article's Creative Commons licence and your intended use is not permitted by statutory regulation or exceeds the permitted use, you will need to obtain permission directly from the copyright holder. To view a copy of this licence, visit http://creativecommons.org/licenses/by/4.0/.

\section{References}

1. Le Saux O, Urban Z, Tschuch C, Csiszar K, Bacchelli B, Quaglino D, Pasquali-Ronchetti I, Pope FM, Richards A, Terry S, Bercovitch L, de Paepe A, Boyd CD (2000) Mutations in a gene encoding an $\mathrm{ABC}$ transporter cause pseudoxanthoma elasticum. Nat Genet 25: 223-227

2. Le Saux O, Martin L, Aherrahrou Z, Leftheriotis G, Váradi A, Brampton CN (2012) The molecular and physiological roles of ABCC6: more than meets the eye. Front Genet 3:289
3. Jansen RS, Duijst S, Mahakena S, Sommer D, Szeri F, Váradi A, Plomp A, Bergen AA, Oude Elferink RPJ, Borst P, van de Wetering $\mathrm{K}$ (2014) ABCC6-mediated ATP secretion by the liver is the main source of the mineralization inhibitor inorganic pyrophosphate in the systemic circulation-brief report. Arterioscler Thromb Vasc Biol 34:1985-1989

4. Jansen RS, Küçükosmanoglu A, de Haas M, Sapthu S, Otero JA, Hegman IEM, Bergen AAB, Gorgels TGMF, Borst P, van de Wetering K (2013) ABCC6 prevents ectopic mineralization seen in pseudoxanthoma elasticum by inducing cellular nucleotide release. Proc Natl Acad Sci U S A 110:20206-20211

5. Charbel Issa P, Finger RP, Götting C, Hendig D, Holz FG, Scholl HPN (2010) Centrifugal fundus abnormalities in pseudoxanthoma elasticum. Ophthalmology 117:1406-1414

6. Charbel Issa P, Finger RP, Holz FG, Scholl HPN (2009) Multimodal imaging including spectral domain OCT and confocal near infrared reflectance for characterization of outer retinal pathology in pseudoxanthoma elasticum. Invest Ophthalmol Vis Sci 50:5913-5918

7. Gliem M, de Zaeytijd J, Finger RP, Holz FG, Leroy BP, Charbel Issa $P$ (2013) An update on the ocular phenotype in patients with pseudoxanthoma elasticum. Front Genet 4:14

8. Gliem M, Müller PL, Birtel J, Hendig D, Holz FG, Charbel Issa P (2016) Frequency, phenotypic characteristics and progression of atrophy associated with a diseased Bruch's membrane in pseudoxanthoma elasticum. Invest Ophthalmol Vis Sci 57:3323

9. Birtel J, Lindner M, Mishra DK, Müller PL, Hendig D, Herrmann P, Holz FG, Fleckenstein M, Gliem M, Charbel Issa P (2019) Retinal imaging including optical coherence tomography angiography for detecting active choroidal neovascularization in pseudoxanthoma elasticum. Clin Exp Ophthalmol 47:240-249

10. Gliem M, Finger RP, Fimmers R, Brinkmann CK, Holz FG, Charbel Issa P (2013) Treatment of choroidal neovascularization due to angioid streaks: a comprehensive review. Retina 33:13001314

11. Finger RP, Fenwick E, Marella M, Charbel Issa P, Scholl HPN, Holz FG, Lamoureux EL (2011) The relative impact of vision impairment and cardiovascular disease on quality of life: the example of pseudoxanthoma elasticum. Health Qual Life Outcomes 9:113

12. Risseeuw S, Ossewaarde-van Norel J, Klaver CCW, Colijn JM, Imhof SM, van Leeuwen R (2018) Visual acuity in pseudoxanthoma elasticum. Retina (Philadelphia, Pa)

13. Holash J, Davis S, Papadopoulos N, Croll SD, Ho L, Russell M, Boland P, Leidich R, Hylton D, Burova E, Ioffe E, Huang T, Radziejewski C, Bailey K, Fandl JP, Daly T, Wiegand SJ, Yancopoulos GD, Rudge JS (2002) VEGF-trap: a VEGF blocker with potent antitumor effects. Proc Natl Acad Sci U S A 99:1139311398

14. Nguyen QD, Shah SM, Hafiz G, Quinlan E, Sung J, Chu K, Cedarbaum JM, Campochiaro PA (2006) A phase I trial of an IV-administered vascular endothelial growth factor trap for treatment in patients with choroidal neovascularization due to age-related macular degeneration. Ophthalmology 113: 1522.e1-1522.e14

15. Heier JS, Brown DM, Chong V, Korobelnik J-F, Kaiser PK, Nguyen QD, Kirchhof B, Ho A, Ogura Y, Yancopoulos GD, Stahl N, Vitti R, Berliner AJ, Soo Y, Anderesi M, Groetzbach G, Sommerauer B, Sandbrink R, Simader C, Schmidt-Erfurth U (2012) Intravitreal aflibercept (VEGF trap-eye) in wet age-related macular degeneration. Ophthalmology 119:2537-2548

16. Ikuno Y, Ohno-Matsui K, Wong TY, Korobelnik J-F, Vitti R, Li T, Stemper B, Asmus F, Zeitz O, Ishibashi T (2015) Intravitreal Aflibercept injection in patients with myopic choroidal 
neovascularization: the MYRROR study. Ophthalmology 122: $1220-1227$

17. Diago T (2016) Treat and extend regimen with aflibercept for choroidal neovascularization in angioid streaks. Eye 30:637639

18. Esen E, Sizmaz S, Demircan N (2015) Intravitreal aflibercept for management of subfoveal choroidal neovascularization secondary to angioid streaks. Indian J Ophthalmol 63:616-618

19. Tetikoglu M, Sagdik HM, Aktas S, Ozcura F (2016) Intravitreal aflibercept for refractory choroidal neovascularization secondary to angioid streaks. Eye 30:894-895

20. Vaz-Pereira S, Collaço L, de Salvo G, van Zeller P (2015) Intravitreal aflibercept for choroidal neovascularisation in angioid streaks. Eye 29:1236-1238

21. Sekfali R, Mimoun G, Cohen SY, Querques G, Bandello F, Sacconi R, Souied EH, Capuano V (2019) Switching from ranibizumab to aflibercept in choroidal neovascularization secondary to angioid streaks. Eur J Ophthalmol. https://doi.org/10.1177/ 1120672119838133

22. Mangione CM, Lee PP, Gutierrez PR, Spritzer K, Berry S, Hays RD (2001) Development of the 25-item national eye institute visual function questionnaire. Arch Ophthalmol 119:1050-1058

23. Finger RP, Charbel Issa P, Hendig D, Scholl HPN, Holz FG (2011) Monthly ranibizumab for choroidal neovascularizations secondary to angioid streaks in pseudoxanthoma elasticum: a one-year prospective study. Am J Ophthalmol 152:695-703

24. Lai TYY, Staurenghi G, Lanzetta P, Holz FG, Melissa Liew SH, Desset-Brethes S, Staines H, Hykin PG (2018) Efficacy and safety of ranibizumab for the treatment of choroidal neovascularization due to uncommon cause: twelve-month results of the MINERVA study. Retina 38:1464-1477

25. Lefthériotis G, Omarjee L, Le Saux O, Henrion D, Abraham P, Prunier F, Willoteaux S, Martin L (2013) The vascular phenotype in Pseudoxanthoma elasticum and related disorders: contribution of a genetic disease to the understanding of vascular calcification. Front Genet 4:4

26. Gliem M, Birtel J, Müller PL, Hendig D, Faust I, Herrmann P, Holz FG, Adamus G, Charbel Issa P (2019) Acute Retinopathy in Pseudoxanthoma Elasticum. JAMA Ophthalmol 137:1165-1173

27. Hess K, Gliem M, Birtel J, Müller P, Hendig D, Andrews C, Murray IJ, Holz FG, Charbel Issa P (2019) Impaired dark adaptation associated with a diseased Bruch membrane in pseudoxanthoma elasticum. Retina. https://doi.org/10.1097/IAE.0000000000002689

Publisher's note Springer Nature remains neutral with regard to jurisdictional claims in published maps and institutional affiliations. 